\title{
Review \\ Breast cancer cell lines: friend or foe?
}

\section{Sarah E Burdall ${ }^{1,2}$, Andrew M Hanby ${ }^{3}$, Mark RJ Lansdown² and Valerie Speirs ${ }^{1}$}

\author{
${ }^{1}$ Molecular Medicine Unit, University of Leeds, Leeds, UK \\ ${ }^{2}$ Breast Unit, St James's University Hospital, Leeds, UK \\ ${ }^{3}$ Academic Unit of Pathology, University of Leeds, Leeds, UK \\ Corresponding author: Valerie Speirs (e-mail v.speirs@leeds.ac.uk)
}

Received: 8 November 2002 Revisions received: 10 January 2003 Accepted: 20 January 2003 Published: 3 February 2003

Breast Cancer Res 2003, 5:89-95 (DOI 10.1186/bcr577)

(C) 2003 BioMed Central Ltd (Print ISSN 1465-5411; Online ISSN 1465-542X)

\begin{abstract}
The majority of breast cancer research is conducted using established breast cancer cell lines as in vitro models. An alternative is to use cultures established from primary breast tumours. Here, we discuss the pros and cons of using both of these models in translational breast cancer research.

Keywords: cell culture, in vitro models, mammary gland
\end{abstract}

\section{Introduction}

Cell lines are widely used in many aspects of laboratory research and particularly as in vitro models in cancer research. They have a number of advantages; for example, they are easy to handle and represent an unlimited selfreplicating source that can be grown in almost infinite quantities. In addition, they exhibit a relatively high degree of homogeneity and are easily replaced from frozen stocks if lost through contamination. However, there are disadvantages. Cell lines are prone to genotypic and phenotypic drift during their continual culture. This is particularly common in the more frequently used cell lines, especially those that have been deposited in cell banks for many years. Subpopulations may arise and cause phenotypic changes over time by the selection of specific, more rapidly growing clones within a population. This was highlighted by Osborne and colleagues [1], who demonstrated many discrepancies in the most commonly used breast cancer cell line, namely MCF-7, obtained from different laboratories. As well as variations in cell growth rate, changes were observed in hormone receptor content, karyotype and clonogenicity, despite the cells appearing morphologically identical. Using 24-colour fluorescent in situ hybridization, this observation has again come to the fore, with MCF-7 cells from different UK laboratories showing markedly different karyotypes [2].
Thus, there is substantial evidence not only for intralaboratory cell line heterogeneity within established cell lines, but also for drift away from the phenotype of the originating tumour. This is a cause for serious concern, especially if such cell lines are to be regarded as valid models for evaluating the pathobiology of breast cancer and/or the likely response to novel drug therapies.

\section{'False' cell lines}

Another important consideration, which has largely been ignored over the years, is the concept of 'false' cell lines. This was first highlighted over 20 years ago by the demonstration that a large number of cell lines were contaminated with HeLa cells [3]. HeLa was the first cell line to be developed in 1952, from a glandular cancer of the cervix [4]. The HeLa cell line has since become notorious as a cross-contaminant of many other cell lines.

The increasing misuse of 'false' cell lines has recently come to light in the literature, with the observation that of 252 new cell lines deposited at the German Cell Line Bank, nearly one-fifth of these (18\%) were found to be cross-contaminants $[5,6]$. It has been suggested that many referees and editors of journals are unaware of the extent of this cross-contamination problem. Thus, for cell lines to be used as models in a meaningful way, it is imper- 
Table 1

\begin{tabular}{|c|c|c|c|c|c|}
\hline Cell line & Origin & Age (years) & Pathology & Citations & Reference \\
\hline BT20 & Breast & 74 & Invasive ductal carcinoma & 260 & [9] \\
\hline MDA-MB-231 & Pleural effusion & 51 & Adenocarcinoma & 1157 & {$[10,11]$} \\
\hline MDA-MB-435 & Pleural effusion & 31 & Invasive ductal carcinoma & 292 & [11] \\
\hline MDA-MB-468 & Pleural effusion & 51 & Adenocarcinoma & 223 & [11] \\
\hline MCF-7 & Pleural effusion & 69 & Invasive ductal carcinoma & 5774 & [8] \\
\hline SkBr3 & Pleural effusion & 43 & Adenocarcinoma & 203 & [12] \\
\hline T47D & Pleural Effusion & 54 & Invasive ductal carcinoma & 866 & [13] \\
\hline ZR75.1 & Ascites & 47 & Invasive ductal carcinoma & 590 & [14] \\
\hline
\end{tabular}

ative that they are well characterized before embarking on a programme of research.

A potential answer to this problem would be for all journals to demand that any cell lines be thoroughly identified and characterized before the publication of results. This can be conducted in number of ways, including HLA typing, karyotyping, isoenzyme typing and DNA fingerprinting. However these tests are difficult to reproduce and can be costly. The use of short tandem repeat (STR) profiling has been proposed as a potentially easier, cheaper, and more reliable and reproducible way of screening cell lines [7]. First developed for forensic use, STR profiling can also be used to validate cell lines by employing a standard set of STR primers to detect a number of polymorphic STR loci using commercially available oligonucleotide primers [7]. Analysis of 253 cell lines from a number of sources worldwide using STR profiling resulted in a highly accurate numerical code, akin to a cell line specific 'barcode' that relates to the length of specific polymerase chain reaction products amplified at each locus [7]. This can provide a universal reference standard against which human cell lines may be compared. Since the late 1960s, researchers have recognized the importance of testing cultured cells for possible mycoplasma infection, which can invalidate results; in the 21 st century, STR profiling now deserves equal recognition and should become a routine procedure in research laboratories.

\section{Long-established breast cancer cell lines}

Apart from MCF-7, which was derived in the Michigan Cancer Foundation (from which it derives its name) in 1973 from a pleural effusion [8] and which is the most commonly used breast cancer cell line in the world, a number of other cell lines are routinely used as breast cancer models. Some of the most common are shown in been cited in scientific literature over a defined period of time. However, apart from the pitfalls described above in cell line work, as illustrated in Table 1 most of these long established breast cancer cell lines in current use are not derived from primary breast tumours, but from tumour metastases, especially aspirates or pleural effusions. This means that the majority of such cell lines are derived from more aggressive and often metastatic tumours, rather than the primary lesion. This is clearly unrepresentative of the diverse types of tumour, which are reflected by the specific types, the various grades or stages, and indications for tumour progression that are observed in primary breast cancer. Thus, research that relies on such lines will be biased toward more rapidly progressive types of breast carcinoma and to late-stage disease, rather than lower grade and earlier stage breast cancers. For these reasons it would be more clinically relevant to use cells that are derived directly from a primary tumour, particularly because most drug therapies are directed against these.

\section{Recently established breast cancer cell lines}

Apart from the more traditional breast cancer cell lines detailed above, a number of novel breast cancer cell lines have been established and characterized in recent years [15-18]. Some of these have the advantage of being established from the primary lesion rather than from a distant metastasis. Establishing these new lines has been a lengthy process that requires patience, with most taking several months to meet the recognized criteria of a bona fide continuous cell line. This includes altered cytomorphology, increased growth, reduced serum dependency, increased clonogenicity, a tendency toward anchorageindependent growth, changes in ploidy, tumourigenicity in nude mice and an infinite lifespan [19].

Two studies have compared the characteristics of recently established breast cancer cell lines with those of the 
tumour from which they were isolated $[17,18]$. Good concordance was observed in terms of morphology (87\%), immunohistochemical analysis of oestrogen and progesterone receptors ( $87 \%$ and $73 \%$, respectively), HER2/neu (93\%), p53 (100\%) and allelic loss (82-100\%). A related study used comparative genomic hybridization to determine recurrent genetic alterations in 38 breast cancer cell lines, and the extent to which these cell lines resembled uncultured tumours [20]. As well as more recently established cell lines, that study also included some of the long established cell lines detailed in Table 1. The most common chromosomal gains were seen in $1 p, 1 q, 3 q, 5 p$, $7 p, 7 q, 8 q, 17 q, 20 p$ and $20 q$, with losses observed in $1 p$, $4 p, 8 p, 10 q, 11 q, 18 p, 18 q, 19 p, X p$ and Xq. An average of 19 genetic changes was observed, with nine losses and 10 gains per cell line, which is 2.5 more alterations per cell line as compared with tumours; however, the most prominent alterations were the same. A number of highlevel amplifications were also observed in the cell lines that were previously reported in breast tumours. Although several recurrent and high-level amplifications were observed in these cell lines, some of which have also been noted in uncultured breast cancers (e.g. 1q32, 8p11, $8 q 23,11 q 13,17 q 23,17 q 24$ and 20q13), many amplification sites were novel (e.g. 1p13, 7q21, 7q31, 9p23 and 11p13). These may represent changes associated with culture in vitro. Although no direct comparisons were made between chromosome changes in traditional cell lines versus those that were recently established, the 10 most highly upregulated genes were observed in three of the former (MCF-7, SKBr3, ZR75.1wt) and only one of the latter (SUM52). Notably, however, SUM52 was derived from a pleural effusion rather than directly from a primary breast lesion [21].

Another study used comparative genomic hybridization to identify chromosomal change in a panel of 11 novel and well characterized breast cancer cell lines established from primary tumours [22]. This showed several recurrent chromosomal gains at $1 \mathrm{q}, 3 \mathrm{q}$ and $8 \mathrm{q}$. These findings are consistent with those in fresh tumour material [23]. Thus, these more recently established cell lines are potentially more representative of breast cancer as a whole, because many different tumour types, grades and stages can be represented. Clearly, these new cell lines are attractive models, and because some of these have been deposited in the recognized cell banks (e.g. American Type Culture Collection; http://www.atcc.org) they are now commonly available to breast cancer researchers.

\section{Primary cell culture}

A viable alternative to using cell lines, either traditional or more recently derived, is to prepare primary cultures derived directly from tumours. This has a number of advantages. Not only are cells directly isolated from the tumour site, but also detailed pathology is available to allow the characteristics of the culture to be compared with those of the original tumour. Broadly speaking, such cultures can be established either as explants, in which mixed cell populations grow out from small fragments of tissue, or as enriched populations of defined cell types, the latter being more desirable.

\section{Explant culture}

Initial attempts at primary culture of breast tumours met with limited success because of overgrowth of epithelial cells with stromal fibroblasts, aptly described as 'weeds in the tissue culturist's garden' [24]. Fibroblasts quickly adapt to in vitro conditions by proliferating rapidly and outgrowing their slower epithelial neighbours. This is a particular problem with explants, and so researchers have turned to separating enriched populations of defined cell types to overcome this.

\section{Culture of individual cells}

The most straightforward of these methods is the spillage technique, originally described over 40 years ago [25]. This involves cutting the tumour and collecting the cells, which spill out from the cut surface. This has been used successfully in recent years by McCallum and Lowther [16], who were able to establish 10 new cell lines from 135 unselected primary breast tumours.

Most other published protocols have relied on enzymatic dispersal of tumour fragments following mechanical disaggregation of tumour fragments. A partial enzymatic degradation of tumour stroma for up to 6 hours has been described [26] and permits the enrichment and expansion of breast epithelial cells in vitro. Approximately $66 \%$ of samples gave rise to tumour epithelial cells with proliferative capacity. The same group described a sandwich culture [27], in which dissociated breast tumour cells are sandwiched between two glass microscope slides. The slides are immersed in culture medium, which fills the gap between the two slides, creating a natural diffusion gradient for oxygen, nutrients and metabolic waste products. Under these conditions only malignant cells can survive, displaying the cytokeratin (CK) profile associated with lumenal epithelia, predominantly CK7, 8, 18 and 19, and lacking CK4 and 5 [27].

Other techniques rely on the differing sedimentation rates for cells of different size and use a differential centrifugation technique for cell separation. This is carried out after enzymatic dispersal of tissue fragments, the most efficient being collagenase III [28]. First described by Emerman and Wilkinson [29], this technique has been modified and improved by our group and is a robust technique for shortterm culture of epithelial-enriched cells [30]. This technique allows propagation of sufficient quantities of cells with defined phenotype suitable for subsequent cell and molecular biology studies [30-32]. The method is outlined 
Figure 1

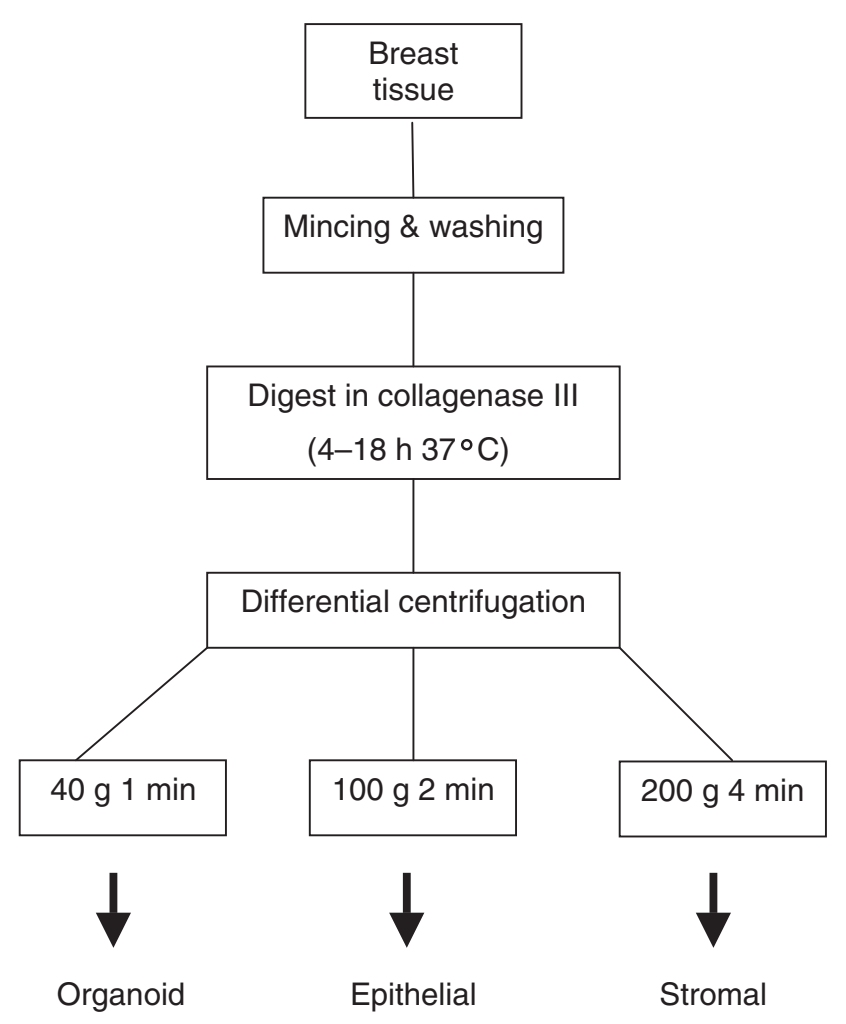

Breast tissue dispersal.

in Fig. 1. It results in three individual fractions from the tissue digest, termed organoid, epithelial and stromal.

The organoid fraction results from small fragments of partly digested tissue, from which an outgrowth of cells is observed (Fig. 2a). Because this is an heterogeneous population, containing both epithelial and fibroblast cells, the fibroblasts can outgrow the epithelial cells unless precaution are taken. This is achieved by the use of a well defined basal media that lacks serum. The main drawback with this fraction, as with explant cultures, is that it may give rise to a population of rapidly proliferating genetically normal cells $[30,33]$.

The epithelial fraction consists of predominantly single cells with the classical cobblestone morphology seen in epithelial cells (Fig. 2b). With increasing time in selective media, these cells can be expanded preferentially and have been characterized by immunohistochemical, biochemical and molecular biology techniques, as well as flow cytometry [30-32]. The fibroblast fraction yields cells with a bipolar spindle shape that is typical of fibroblasts (Fig. 2c) when cultured in media supplemented with heatinactivated foetal bovine serum, and they have also been characterized using the techniques referred to above [30-32].
Figure 2
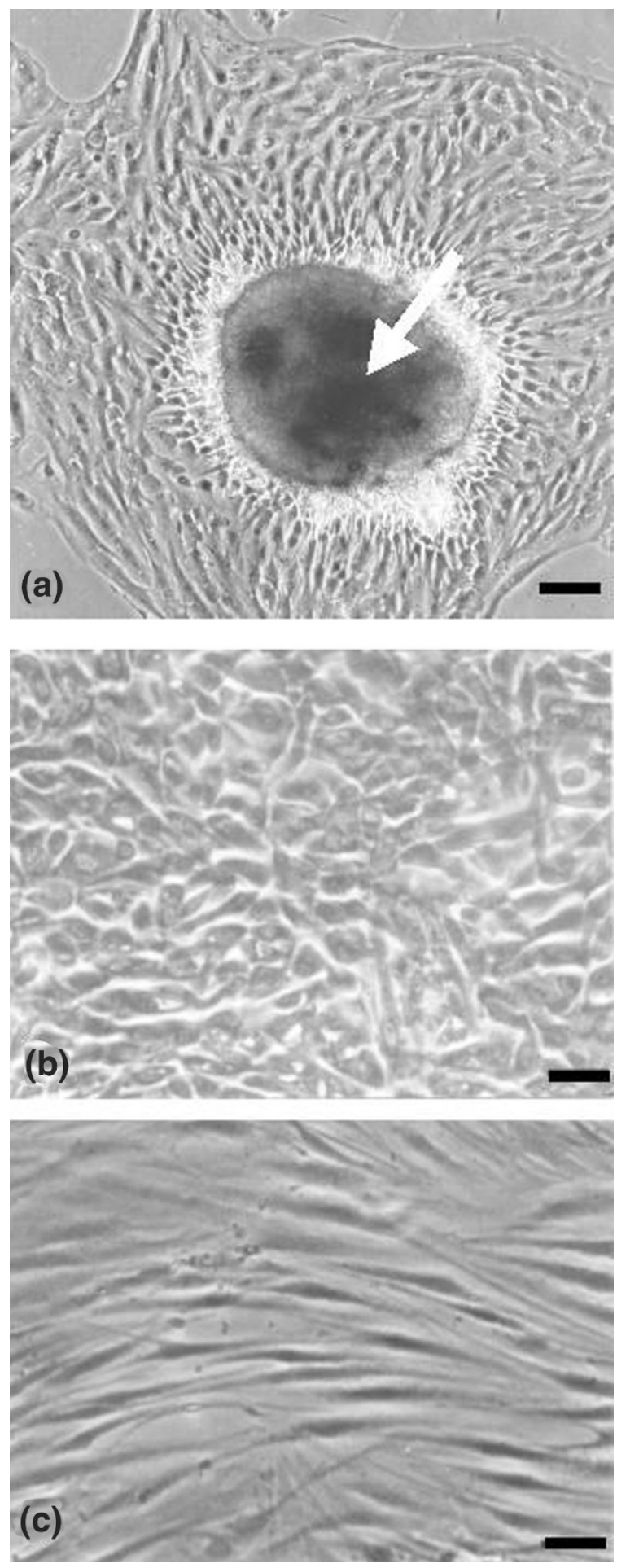

Morphological appearance of the three cell fractions following differential centrifugation followed by culture in selective medium. (a) Organoid fraction. The arrow illustrates a fragment of partially digested tumour that attaches to the substrate of the culture vessel and from which cells with an epithelial-like morphology migrate radially and proliferate. (b) Epithelial fraction. (c) Stromal fraction consisting of fibroblasts. Scale bar $=15 \mu \mathrm{m}$. 
Following dispersal to single cells, immunomagnetic separation has been used to specifically enrich populations of cells from the normal mammary gland [34,35]. This uses magnetic beads covalently coated with an antibody specific to the cell of interest, usually a surface marker. The antibody-coated beads bind to cells that express the specific antigen, and they are extracted from the cell suspension by applying a magnet to the wall of the culture vessel and then decanting any unbound cells. Despite its success with normal mammary tissue, however, there are no reports in the literature of its successful use to isolate epithelial cells from breast tumours.

\section{Pros and cons of breast primary culture}

There are many benefits to be gained from using enriched primary cultures. In some cases, cells are only maintained in culture for a finite length of time, and they have little opportunity to undergo the transformations that are seen in the long-term culture of immortalized cell lines. However, there is the possibility that cells isolated from a breast tumour may behave differently in culture as compared with their response when they are part of a tissue/organ, because the cell-cell interactions that exist in tissue are lost in vitro.

Primary culture does have limitations. These include slow population doubling times and the finite lifespan before senescence; often cells will only survive two or three passages. For some experimental techniques large numbers of cells are required, which can sometimes be a limiting factor because this often cannot be achieved until after several passages. We are currently addressing this by comparing the growth rate of primary epithelial cells in the organoid medium we used originally [30] with keratinocyte serum-free medium supplemented with bovine pituitary extract and recombinant epidermal growth factor. When cultured in the latter, cells appear to have an increased growth rate and lifespan, as judged by an increase in initial cell yield and the ability to undergo a greater number of passages without appreciable change in phenotype (Burdall SE, Speirs V, unpublished data). Furthermore, for some tumours such as infiltrating grade I ductal carcinomas and tubular carcinomas, in which mitotic activity is never or hardly ever evident in whole sections, it appears likely that even use of an enrichment technique will not provide an appropriate in vitro model, because the doubling times would be so prolonged.

Another challenge faced by scientists trying to establish cultures of breast tumour epithelial cells is possible contamination by normal epithelial cells, because tumours are heterogeneous. Phenotypically, there is no clear distinction between cultured tumour and normal epithelium with the former easy to culture, even from tumours [16]. Because tumours are derived from lumenal epithelium, immunopositivity for cytokeratin CK7, 8, 18 and 19 [36] is often used to distinguish tumour from normal. CK19 has proved particularly popular in this regard [27,30,32]. However, culture conditions can selectively influence cell phenotype and CK19 expression can be induced in vitro, even in normal mammary epithelial cells $[16,37]$. Thus, for experiments conducted in low passage $\mathrm{CK} 19^{+}$cells presumed to be tumour cells, additional more robust markers are essential (e.g. telomerase) [38].

\section{Other culture methods}

Although short-term culture of isolated tumour cells has, in our hands, proved successful in a number of different laboratory applications [30-32], it is still an imperfect model because mechanical/enzymatic disaggregation disrupts the normal tissue architecture and cell-cell communications that clearly exist in vivo. One way to maintain these features is the tissue slice method, which was originally described for culture of breast and colon tumours [39]. This involves preparing 400- $\mu \mathrm{m}$ thick tissue slices (thus allowing adequate diffusion of nutrients from the culture medium) from freshly excised tumour and placing them in vitro for up to 6 days, during which time cells continue to proliferate, as judged by uptake of BrdU [39]. Afterward, the tissue can be fixed and processed for immunohistochemistry and analysis by light microscopy. Because of the fact that tissue architecture is maintained, this type of culture has obvious benefits and it is proving particularly useful in studies of prostate cancer (Maitland NJ, personal communication).

Other ways to recreate in vivo conditions are three-dimensional culture systems, which allow the recombination of epithelial and stromal cells usually in semisolid matrices such as Matrigel [40-42]. The ability to culture stromal cells independently from epithelial cells offers the possibility of these types of experiments, allowing the recreation, under controlled conditions, of the cell interactions that exist in vivo.

Successful breast primary culture has also been achieved using irradiated feeder layers of NIH 3T3 cells [43]. The rationale behind using feeder layers is that they allow epithelial-mesenchymal interactions. Krasna and colleagues [43] reported growth of cells of luminal phenotype (as judged by expression of CK19) in 37/38 primary tumour specimens following collagenase digestion of tumour fragments and subsequent plating on ЗТЗ feeder layers. Although they grew for 2-20 passages in vitro, they were not found to be tumourigenic in nude mice, casting doubt on their phenotype.

\section{Ethical approval and tissue availability}

A fundamental issue, which must be addressed before considering using human clinical material for research, is that of patient consent, which is now strictly controlled in the UK following the Redfern report on organ retention [44]. For therapeutic reasons, surgery always removes 
more than is necessary to diagnose; often, tumour excess to that required for diagnosis and staging is left over. Previously considered 'surgical waste', it was relatively straightforward to obtain this material fresh from a cooperative breast surgeon and/or pathologist with the assumption of implicit consent, but nowadays explicit patient consent must always be sought. For this work to be a success, the support of an enthusiastic collaborating pathologist is also essential to provide the most macroscopically representative area of tumour. During the course of our own research we have noticed that breast tumours are becoming smaller through earlier diagnosis, partly because of greater patient awareness and probably also as a result of the UK Breast Screening Programme, introduced in 1988, with national implementation by the mid-1990s. The first priority must be given to pathological diagnosis, and often this means that scientists are left with increasingly smaller amounts of tumour for research. However, because viable tumour cells can successfully be isolated and expanded from a fine needle aspirate [45], this need not be an issue. Indeed, in our experience successful breast primary culture is due to a patient and meticulous approach rather than directly proportional to the amount of starting material.

\section{Novel applications of primary culture for translational research}

There is considerable ethical pressure on scientists to reduce or eliminate the use of animals in laboratory research, and primary cell culture may be one way forward, especially in preclinical drug testing. Another hot area is to predict how patients will respond to chemotherapy regimens. This has recently been addressed in the extreme drug resistance assay, which involves culturing viable tumour specimens in agarose for 5 days in the presence of chemotherapeutic drugs (for review [46]). Tritiated thymidine is then added for the final 48 hours and liquid scintillation counting assesses the amount of radioactive label that has been incorporated (indicative of cell proliferation). This method has recently been piloted in breast tumours. The technique was most successful when tumours exceeded $1 \mathrm{~g}$, were of high grade, were from younger patients and lacked expression of progesterone receptor [47]. Overall, 70\% of samples tested provided information on chemotherapy resistance, suggesting that selection of the most appropriate adjuvant therapy could be guided by in vitro results.

A similar approach is the predictive 3-[4,5-dimethylthiazol2-yl]-2,5-diphenyltetrazolium (MTT) assay, in which dissected tumour biopsies of approximately $1 \mathrm{~mm}^{3}$ are cultured with chemotherapeutic drugs at concentrations designed to mimic the plasma levels achieved in vivo [48]. The 50\% inhibitory concentration is then calculated, based on the conversion of MTT to formazan product. clusion from this study suggested that this was a feasible approach in predicting response to chemotherapy. The tissue slice method [39] described above also has potential here and is currently being evaluated by our group. With the inevitable development of tumour-specific drugs that are tailored to patient requirements, suitability and gene profile, in future breast cancer will no longer be perceived as one disease but rather as an individual entity on a patient-specific basis.

The above techniques have tremendous potential in selecting the most relevant adjuvant chemotherapy. This can only be of benefit to the breast cancer patient, and further trials in this area are warranted.

\section{Conclusion}

Because of their ease of use, there is no doubt that established cell lines will continue to be used as models for breast cancer. However, given the pitfalls discussed above, it is essential that researchers understand their limitations and take these into consideration when designing experiments and interpreting results. Some of the more recently established novel cell lines, particularly those established from primary breast tumours and now available through conventional cell line repositories, are worth considering as research tools. Although more technically demanding to establish, if it is properly characterized, primary culture offers a more relevant clinical model of this disease that is likely to provide more meaningful data. It also offers a better route to cytogenetic analysis (e.g. using 24-colour fluorescent in situ hybridization, which is notoriously difficult to perform on solid tumours). With careful planning and controlled experimentation, together these models will help to enhance our understanding of breast cancer pathobiology.

\section{Competing interests}

None declared.

\section{Acknowledgements}

This work is supported by the Liz Dawn Fund at St James's University Hospital, Leeds, and Yorkshire Cancer Research.

\section{References}

1. Osborne CK, Hobbs K, Trent JM: Biological differences among MCF-7 human breast cancer cell lines from different laboratories. Breast Cancer Res Treat 1987, 9:111-121.

2. Bahia H, Ashman JNE, Cawkwell L, Lind M, Monson JRT, Drew PJ, Greenman J: Karyotypic variation between independently cultured strains of the cell line MCF-7 identified by multicolour fluorescence in situ hybridization. Int J Oncol 2002, 20:489-494.

3. Nelson-Rees WA, Daniels DW, Flandermeyer RR: Cross-contamination of cells in culture. Science 1981, 212: 446-452.

4. Gey GO, Coffman WD, Kubicek MT: Tissue culture studies of the proliferative capacity of cervical carcinoma and normal epithelium. Cancer Res 1952, 12:264-265.

5. MacLeod RAF, Dirks WG, Matsui Y, Kaufmannn M, Milch H, Drexler HG: Widespread intraspecies cross-contamination of human tumor cell lines arising at source. Int J Cancer 1999, 83:555-563.

6. Masters JRW: Human cancer cell lines: fact and fantasy. Nat Rev Mol Biol 2000, 1:233-236.

7. Masters JRW, Thomson JA, Daly-Burns B, Reid YA, Dirks WG, 
Packer P, Toji LH, Ohno T, Tanabe H, Arlett CF, Kelland LR, Harrison M, Virmani A, Ward TH, Ayres KL, Debenham PG: Short tandem repeat profiling provides an international reference standard for human cell lines. Proc Natl Acad Sci USA 2001, 98:8012-8017.

8. Soule HD, Vasquez J, Long A, Albert S, Brennan M: A human cell line from a pleural effusion derived from a breast carcinoma. $J$ Natl Cancer Inst 1973, 51:1409-1413.

9. Ozzello L, Sordat B, Merenda C, Carrel S, Hurlimann J, Mach JP: Transplantation of a human mammary carcinoma cell line (BT 20) into nude mice. J Natl Cancer Inst 1974, 52:1669-1672.

10. Cailleau R, Young R, Olive M, Reeves WJ Jr: Breast tumour cell lines from pleural effusions. J Natl Cancer Inst 1974, 53:661-674.

11. Cailleau R, Olive M, Cruciger OV: Long-term human breast carcinoma cell lines of metastatic origin: preliminary characterization. In Vitro 1978, 14:911-915.

12. Trempe GL: Human breast cancer in culture. Recent Results Cancer Res 1976, 57:33-41.

13. Keydar I, Chen L, Karby S, Weiss FR, Delarea J, Radu M, Chaitcik $\mathrm{S}$, Brenner $\mathrm{HJ}$ : Establishment and characterization of a cell line of human breast carcinoma origin. Eur J Cancer 1979, 15:659-370.

14. Engel LW, Young NA, Tralka TS, Lippman ME, O'Brien SJ, Joyce $\mathrm{MB}$ : Establishment and characterization of three new continuous cell lines derived from human breast carcinomas. Cancer Res 1978, 38:3352-3364.

15. Ethier SP, Mahacek ML, Gullick WJ, Frank Tja ND, Weber BL: Differential isolation of normal luminal mammary epithelial cells and breast cancer cells from primary and metastatic sites using selective media. Cancer Res 1993, 53:627-635.

16. McCallum HM, Lowther GW: Long term culture of primary breast cancer in defined medium. Breast Cancer Res Treat 1996, 39:247-259.

17. Gazdar AF, Kurvari V, Virmani A, Gollahon L, Sakaguchi M, Westerfield M, Kodagoda D, Stasny V, Cunningham HT, Wistuba II, Tomlinson G, Tonk V, Ashfaq R, Leitch AM, Minna JD, Shay JW: Characterization of paired tumor and non-tumor cell lines established from patients with breast cancer. Int $J$ Cancer 1998, 78:766-774.

18. Wistuba II, Behrens C, Milchgrub S, Syed S, Ahmandian M, Virmani AK, Kurvari V, Cunningham TH, Ashfaq R, Minna JD, Gazdar AF: Comparison of features of human breast cancer cell lines and their corresponding tumors. Clin Cancer Res $1998,4: 23931-2938$

19. Freshney RI: Introduction to basic principles. In Animal Cell Culture: a Practical Approach. Edited by Freshney RI. Oxford: IRL Press; 1992:1-14

20. Forozan F, Mahlamaki EH, Monni O, Chen Y, Veldman R, Jiang $Y$, Gooden C, Ethier SP, Kallioiemi A, Kallioniemi O: Comparative genomic hybridization analysis of $\mathbf{3 8}$ breast cancer cell lines: a basis for interpreting complementary DNA microarray data. Cancer Res 2000, 60:4519-4525.

21. Ethier SP, Kokeney KE, Ridings JW, Dilts CA: erbB family receptor expression and growth regulation in a newly isolated human breast cancer cell line. Cancer Res 1996, 56:899-907.

22. Tirkkonen M, Tanner M, Karhu R, Kallioniemi A, Isola J, Kallioniemi OP: Molecular cytogenetics of primary breast cancer by $\mathrm{CGH}$. Genes Chromosomes Cancer 1998, 21:177-184.

23. Forozan F, Veldman R, Ammerman CA, Parsa NZ, Kallioniemi A, Kallioniemi OP, Ethier SP: Molecular cytogenetic analysis of 11 new breast cancer cell lines. Br J Cancer 1999, 81:1328-1334.

24. Freshney Rl: Induction of differentiation in neoplastic cells. Anticancer Res 1985, 5:111-130.

25. Lasfargues EY, Ozzello L: Cultivation of human breast carcinomas. J Natl Cancer Inst 1958, 21:1131-1147.

26. Dairkee SH, Deng G, Stampfer MR, Waldman FM, Smith HS: Partial enzymatic degradation of stroma allows enrichment and expansion of primary breast tumour cells. Cancer Res 1997, 57:1590-1596.

27. Dairkee SH, Deng G, Stampfer MR, Waldman F, Smith HS: Selective culture of primary breast carcinoma. Cancer Res 1995, 55:2516-2519.

28. Speirs V, Green AR, White MC: Collagenase III: a superior enzyme for complete disaggregation and improved viability of normal and malignant human breast tissue. In Vitro Cell Devel Biol 1996, 32:72-74.

29. Emerman JT, Wilkinson DA: Routine culturing of normal, dysplas- tic and malignant human mammary epithelial cells from small tissue samples. In Vitro Cell Develop Biol 1990, 26:1186-1194.

30. Speirs V, Green AR, Walton DS, Kerin MJ, Fox JN, Carleton PJ Desai SB, Atkin SL: Short-term primary culture of epithelial cells derived from human breast tumours. $\mathrm{Br} J$ Cancer 1998, 78:1421-1429.

31. Speirs V, Green AR, Atkin SL: Activity and expression of 17ßhydroxysteroid dehydrogenase type I in primary cultures of epithelial and stromal cells derived from normal and tumourous human breast tissue: the role of IL-8. J Steroid Biochem Molec Biol 1998, 67: 267-274.

32. Loveday RL, Speirs V, Drew PJ, Kerin MJ, Monson JR, Greenman $\mathrm{J}$ : Intracellular flow cytometric analysis of primary cultured breast tumour cells. Cancer Invest 2002, 20:340-347.

33. Wolman SR, Mohamed AN, Heppner GH, Soule HD: Chromosomal markers of immortalization in human breast epithelium. Genes Chromosomes Cancer 1994, 10:59-65.

34. Clarke C, Titley J, Davies S, O'Hare MJ: An immunomagnetic separation method using superparamagnetic (MACS) beads for large-scale purification of human mammary luminal and myoepithelial cells. Epithelial Cell Biol 1994, 3:38-46.

35. Gudjonsson T, Villadsen R, Nielsen HK, Ronnov-Jessen, Bissell MJ, Petersen OW: Isolation, immortalisation, and characterisation of a human breast epithelial cell line with stem cell properties. Genes Devel 2002, 16:693-706.

36. Taylor-Papadimitrou J, Stampfer MS, Bartek J, Lewis A, Boshell M, Lane EB, Leigh IM: Keratin expression in human mammary epithelial cells cultured from normal and malignant tissue: relation to in vivo phenotypes and influence of medium. $J$ Cell Sci 1989, 94:403-413.

37. Ethier SP: Human breast cancer cell lines as models of growth regulation and disease progression. J Mammary Gland Biol Neoplasia 1996, 1:111-121.

38. Imam SA, Kim MS, Anker L, Data RH, Law RE, Taylor CR: Systematic determination of telomerase activity and telomerase length during the progression of human breast cancer in cell culture models. Anticancer Res 1997, 17:4435-4441.

39. Hood CJ, Parham DM: A simple method of tumour culture. Pathol Res Practice 1998, 194:177-181.

40. Biran S, Vlodavsky I, Fuks Z, Lijovetzky G, Horowitz AT: Growth of human mammary carcinoma cells from biopsy specimens in serum-free medium on extracellular matrix. Int $J$ Cancer 1986, 38:345-354.

41. Bergstraesser LM, Weitzman SA: Culture of normal and malignant primary human mammary epithelial cells in a physiological manner simulates in vivo growth patterns and allows discrimination of cell type. Cancer Res 1993, 53:2644-2654.

42. Ip MM, Darcy KM: Three-dimensional mammary primary culture model systems. J Mammary Gland Biol Neoplasia 1996, 1:91-110.

43. Krasna L, Dudorkinova D, Vedralova J, Vesely P, Pokorna E, Kudlackova I, Chaloupkova A, Petruzelka L, Danes J, Matouskova E: Large expansion of morphologically heterogeneous mammary epithelial cells, including the luminal phenotype, from human breast tumours. Breast Cancer Res Treat 2002, 71:219-235.

44. The Report of The Royal Liverpool Children's Inquiry. [http://www.rlcinquiry.org.uk/].

45. Li Z, Bustos V, Miner j, Paulo E, Meng ZH, Zlotnikov G, Ljung B-M, Dairkee S: Propagation of genetically altered tumour cells derived from fine-needle aspirates of primary breast carcinoma. Cancer Res 1998, 58:5271-5274.

46. Fruehauf JP: In vitro assay-assisted treatment selection for women with breast or ovarian cancer. Endocr Relat Cancer 2002, 9:171-182

47. Ellis RJ, Fabian CJ, Kimler BF, Tawfik O, Mayo MS, Decelis CR, Jewell WR, Connor C, Praeger M, McGinness M, Mehta R, Fruehauf JP: Factors associated with the success of the extreme drug resistance assay in primary breast cancer specimens. Breast Cancer Res Treat 2002, 71:95-102.

48. Xu J-M, Song S-T, Tang Z-M, Jiang Z-F, Liu X-O, Zhang J, Liu X-W: Predictive chemotherapy of advanced breast cancer directed by MTT assay in vitro. Breast Cancer Res Treat 1999, 53:77-85.

\section{Correspondence}

Valerie Speirs, Molecular Medicine Unit, Clinical Sciences Building, St James's University Hospital, Leeds LS9 7TF, UK. E-mail: v.speirs@leeds.ac.uk 